\title{
Impact of Various Weather Conditions on Free Space Optics using 4X4 Transmitter/Receiver Combination Integrated with Different Ways of Amplification
}

\author{
Harneet Kaur $^{1}$, Himali Sarangal ${ }^{2}$ \\ Student, Mtech, ECE, Guru Nanak Dev University, Jalandhar, India ${ }^{1}$ \\ Assistant Professor, ECE, Guru Nanak Dev University, Jalandhar, India ${ }^{2}$
}

\begin{abstract}
Due to consistently growing demand for high data rate and high speed wireless access, free space optics has emerged as a next generation high speed wireless communication technology.FSO system using multiple transceivers has several advantages such large link distance and better bit error performance. In this paper, FSO system using spatial diversity technique and three ways of optical amplifications are proposed. Performance Analysis of different amplification systems for various weather conditions is carried out. Parameters such as received power, BER and maximum achievable range are analysed. Multiple transmitter/receiver combination integrated with various amplification types enhances the performance of FSO system.
\end{abstract}

Keywords: Free Space Optics (FSO) link, Multiple TX/RX FSO, Bit error rate (BER), Preamplifier, Optical amplification

\section{INTRODUCTION}

Free Space Optical Communication has attracted receiver. Third system is analysed with optical amplifier at considerable attention recently as it is a technology which the transmitter as well as the receiver. Comparative study offers speed of fiber and flexibility of wireless technology. over these systems is done. By using the feasible Free space optics also known as fibreless optics has many parameters for $4 X 4 \mathrm{TX} / \mathrm{RX}$ combination [12] integrated advantages such as high speed, unregulated bandwidth and with various ways of amplification, performance of FSO protocol independent. [1] It is a cost effective, secure and system can be improved. Performance is analysed on the rapidly deployable last mile wireless access technology basis of maximum achievable distance and bit error rate. which provides data rate up to tens of Gbps [2]. This Section II describes the simulation set up and system technology is least effected by interference and is immune parameters. The section III discusses the results and the to fading which results in less power loss [3]. Despite of paper is concluded in the section IV.

many advantages there are various challenges which limits the system performance. Local weather conditions such as fog, haze and rain severely effects the performance [4][5]. Atmospheric turbulence, Building sway, aerosol scattering effects and mechanical vibrations are also various causes of performance degradation [6]. FSO system can function over several kilometres as long as there is clear line of sight and thus can be effected by various obstructions. Atmospheric losses in the system occur due to absorption, scattering, scintillation and refraction [7]. Beam divergence and pointing error leads to free space losses. [8][9]

Spatial diversity techniques which uses multiple transmitter/receiver combination improves the link performance by reducing fading induced by atmospheric turbulence [10]. This further improves the received power at the receiver. This works focuses on spatial diversity [11] integrated with various ways of amplification systems analysis of performance is done under various weather conditions. Three systems are used. First system has the optical amplifier used at the transmitter known as the preamplifier. Post-Amplification use amplifier at the

\section{SIMULATION SETUP}

The software platform uses optical communication package optisystem 7.0 of Optiwave Company. A 20Gbps high speed atmospheric optical communication model is established based on multiple transceivers integrated with various ways of optical amplification. This FSO system uses 4X4 transmitter/receiver combination which improves the received power and further it is integrated with three types of amplification. Three types of amplifications are used preamplification (system1), postamplification (system 2) and pre-post amplification (system 3).System 1 consists optical transmitter connected to fork. A fork is a component used to duplicate the number of output ports so that each of the signals coming out from fork's output has the same value with the output signal from the previous component connected to it. The first fork produces the multiple beam and this fork is connected to another set of forks which also produces multiple laser beams. These laser beams are combined by the power combiner. An optical amplifier is applied before 
output is given to FSO channel. At the receiver side power coming from the FSO channel is again combined by power combiner and then fed to the optical receiver. Optical power meter, optical spectrum analyser and BER analyser are the three visualizers used in the simulation .[12] The power meter at the transmitter is used to measure the transmit power signal coming out from the transmitter output port and the receiver power meter is used to calculate average received power at the receiver. BER analyzer calculates the bit error rate and displays the eye diagram. System 2 setup is similar with system 1 but amplifier is applied after the FSO channel instead of before FSO channel. In system 3 amplifier are used at receiver as well as the transmitter. Table I shows attenuation offered by various weather conditions at $1550 \mathrm{~nm}$.Table II shows the various system parameters. Figure 1, 2 and 3 shows the block diagram of system 1, 2 and 3 respectively.

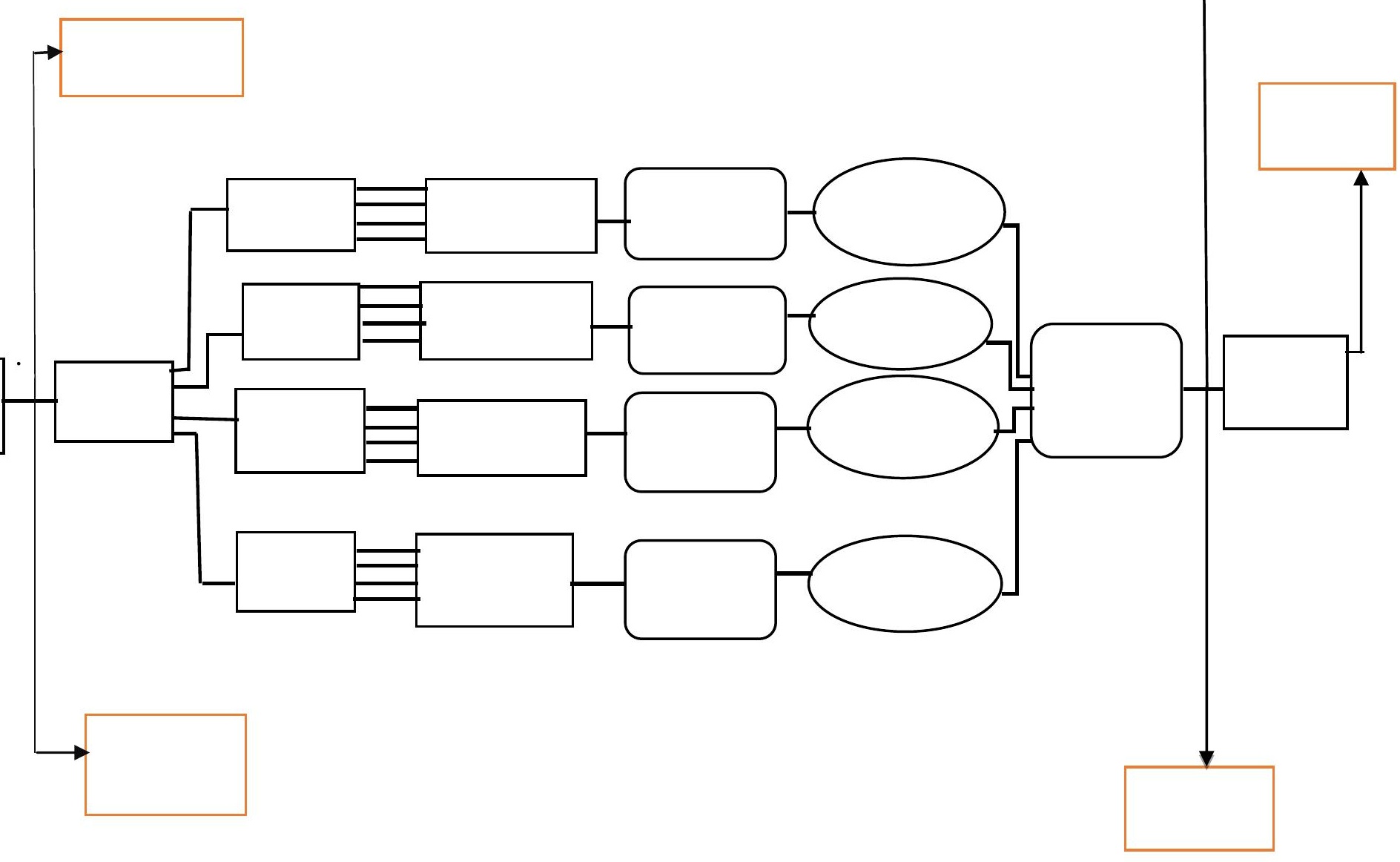

FIG 1: Block diagram of system 1 


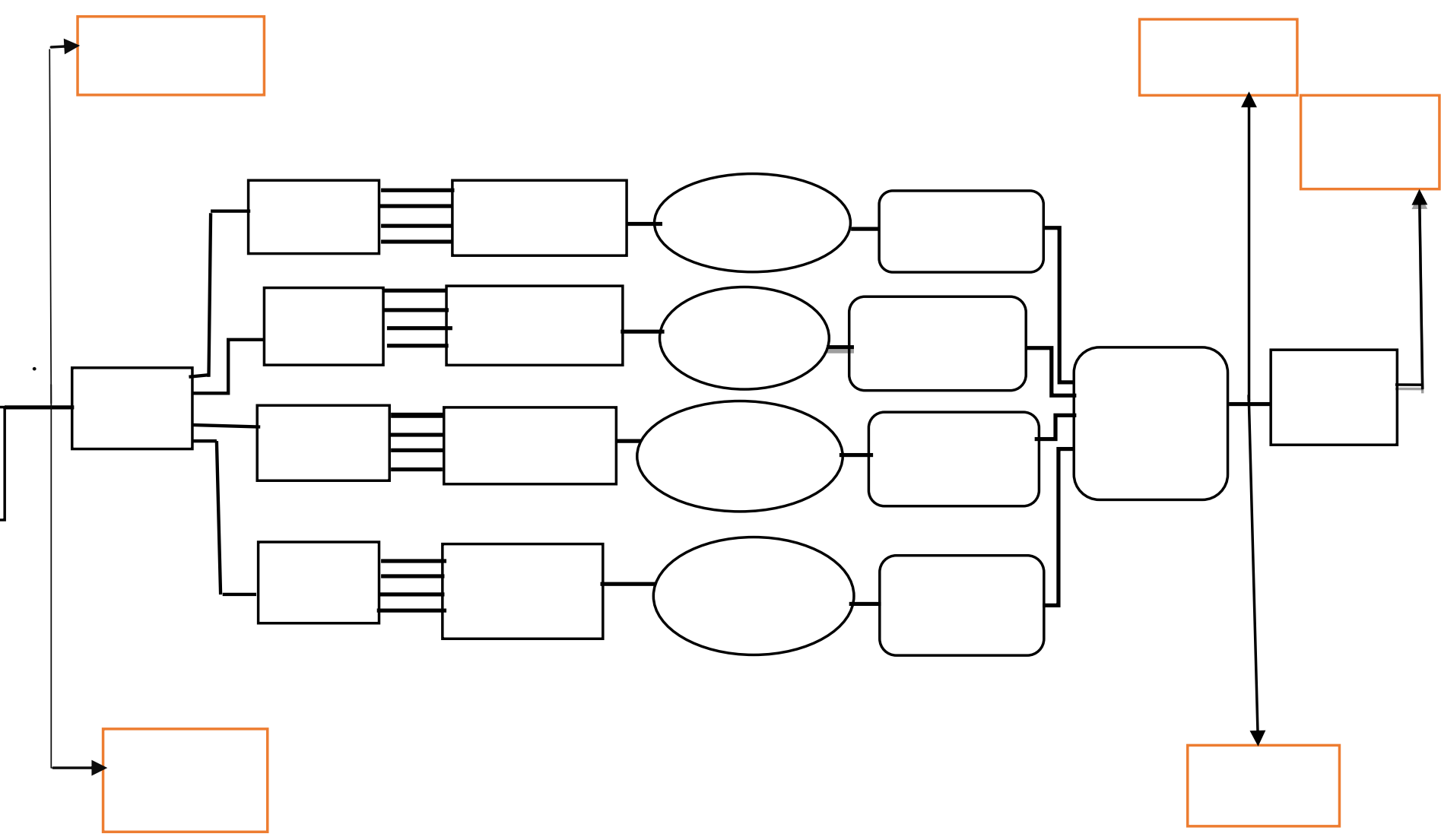

Fig. 2: Block diagram of system 2

TABLE I: Atmospheric attenuation at different weather conditions for $1550 \mathrm{~nm}$ wavelength

\begin{tabular}{|l|l|l|}
\hline $\begin{array}{l}\text { Weather } \\
\text { Conditions }\end{array}$ & $\begin{array}{l}\text { Visibility } \\
(\mathbf{k m})\end{array}$ & Attenuation(dB/Km) \\
\hline Clear air & 23 & 0.1 \\
\hline Haze & 2 & 4.2 \\
\hline Light Fog & 0.8 & 15.5 \\
\hline $\begin{array}{l}\text { Moderate } \\
\text { Fog }\end{array}$ & 0.6 & 25.5 \\
\hline
\end{tabular}

TABLE II: FSO system parameters

\begin{tabular}{|l|l|}
\hline Parameter & Value \\
\hline Transmitted Wavelength & $1550 \mathrm{~nm}$ \\
\hline Data Rate & $20 \mathrm{Gbps}$ \\
\hline Transmitter Aperture & $2.5 \mathrm{~cm}$ \\
\hline Receiver Aperture & $45 \mathrm{~cm}$ \\
\hline Transmitted Power & $25 \mathrm{dBm}$ \\
\hline PIN Responsivity & $1 \mathrm{~A} / \mathrm{W}$ \\
\hline Each Amplifier Gain & $30 \mathrm{~dB}$ \\
\hline Transmitter loss & $1.8 \mathrm{~dB}$ \\
\hline Receiver loss & $1.8 \mathrm{~dB}$ \\
\hline Receiver Sensitivity & $-45 \mathrm{dBm}$ \\
\hline Beam Divergence & $2 \mathrm{mrad}$ \\
\hline
\end{tabular}




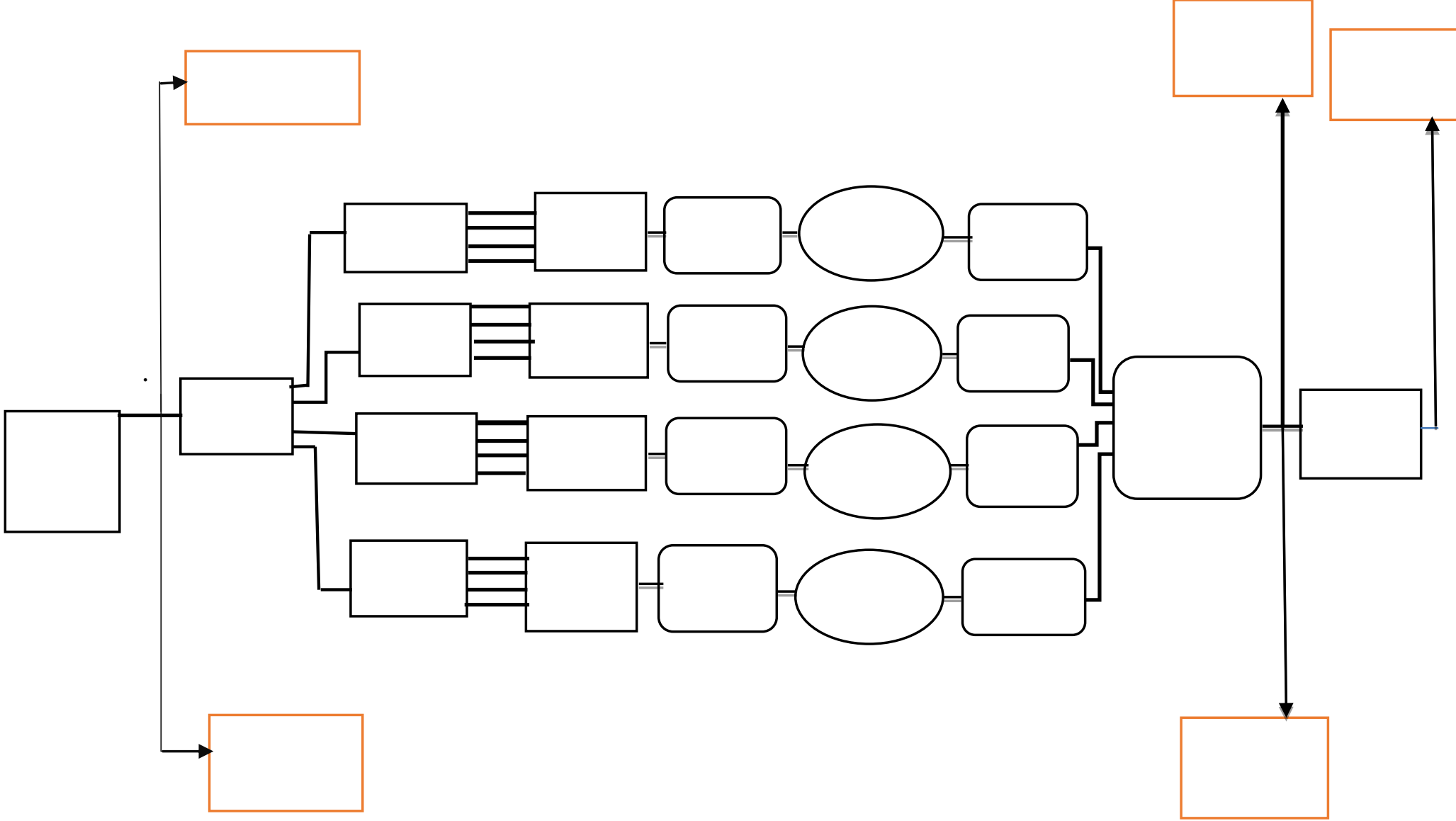

Fig. 3: Block diagram of system 3

\section{III.RESULTS AND DISCUSSION}

In this work, a novel FSO system is modelled in which 1.System 3 also become little costlier and complex 4X4 multiple transmitter/receiver combined with different because of extra optical amplifiers required. Figure 4, ways of amplification. Weather conditions such as fog, figure 5 and figure 6 shows the graph for BER vs range for haze and rain severely effects the FSO system. High data system 1, 2, 3 respectively under clear weather condition. rate of $20 \mathrm{Gbps}$ and wavelength of $1550 \mathrm{~nm}$ is used. Optical System 1 shows the best BER performance as the optical amplification applied enhances the performance of system. signal is amplified at the transmitter, so it avoids being Table III shows the maximum achievable distance at an merged by noise in transmission. For system 2 strong acceptable BER and received power for various weather noise is added in transmission before the signal is conditions for system 1.For clear weather condition the amplified, so its BER performance is worst. System 3 is maximum range of $338 \mathrm{~km}$ can be achieved for system the combination of both system 1 and 2 hence its BER 1.As attenuation increases the maximum achievable performance is better than system 2 but not superior than distance for light fog is $4.56 \mathrm{~km}$.System 2 uses post system 1 .

amplification which has an inferior performance than system 1.System 3 uses optical amplification both at receiver as well as at the transmitter. Table IV and table $\mathrm{V}$ shows the performance of system 2 and system 3 for various weather conditions. System 3 provide us with maximum range up to $310 \mathrm{~km}$ under clear weather condition. System 3 shows the higher received power but BER performance of system 3 is inferior to system 
International Journal of Advanced Research in Computer and Communication Engineering Vol. 4, Issue 3, March 2015

TABLE III: Results of system 1 for different weather conditions

\begin{tabular}{|c|c|c|c|}
\hline $\begin{array}{c}\text { Weather } \\
\text { Condition }\end{array}$ & $\begin{array}{c}\text { Maximum } \\
\text { Range }\end{array}$ & $\begin{array}{c}\text { Received } \\
\text { Power }(\mathbf{d B m})\end{array}$ & $\begin{array}{c}\text { Received } \\
\text { BER }\end{array}$ \\
\hline Clear Air & $338 \mathrm{~km}$ & $-36.546 \mathrm{dBm}$ & $2.95 \mathrm{e}^{-009}$ \\
\hline Haze & $14.5 \mathrm{~km}$ & $-36.302 \mathrm{dBm}$ & $1.001 \mathrm{e}^{-009}$ \\
\hline Light Fog & $4.56 \mathrm{~km}$ & $-36.05 \mathrm{dBm}$ & $3.07 \mathrm{e}^{-010}$ \\
\hline Moderate Fog & $2.92 \mathrm{~km}$ & $-35.97 \mathrm{dBm}$ & $2.101 \mathrm{e}^{-010}$ \\
\hline
\end{tabular}

TABLE IV: Results of system 2 for different weather conditions

\begin{tabular}{|l|l|l|l|}
\hline $\begin{array}{l}\text { Weather } \\
\text { Condition }\end{array}$ & $\begin{array}{l}\text { Maximum } \\
\text { Range }\end{array}$ & $\begin{array}{l}\text { Received } \\
\text { Power }\end{array}$ & $\begin{array}{l}\text { Received } \\
\text { BER }\end{array}$ \\
\hline Clear Air & $105 \mathrm{~km}$ & $6.692 \mathrm{dBm}$ & $4.613 \mathrm{e}^{-009}$ \\
\hline Haze & $7.8 \mathrm{~km}$ & $6.725 \mathrm{dBm}$ & $9.66 \mathrm{e}^{-010}$ \\
\hline Light Fog & $2.7 \mathrm{~km}$ & $6.736 \mathrm{dBm}$ & $5.734 \mathrm{e}^{-010}$ \\
\hline Moderate Fog & $1.78 \mathrm{~km}$ & $6.743 \mathrm{dBm}$ & $4.18 \mathrm{e}^{-010}$ \\
\hline
\end{tabular}

TABLE V: Results of system 3 for different weather conditions

\begin{tabular}{|l|l|l|l|}
\hline $\begin{array}{l}\text { Weather } \\
\text { Condition }\end{array}$ & $\begin{array}{l}\text { Maximum } \\
\text { Range }\end{array}$ & $\begin{array}{l}\text { Received } \\
\text { Power }\end{array}$ & $\begin{array}{l}\text { Received } \\
\text { BER }\end{array}$ \\
\hline Clear Air & $310 \mathrm{~km}$ & $6.701 \mathrm{dBm}$ & $2.85 \mathrm{e}^{-009}$ \\
\hline Haze & $13.8 \mathrm{~km}$ & $6.709 \mathrm{dBm}$ & $2.09 \mathrm{e}^{-009}$ \\
\hline Light Fog & $4.36 \mathrm{~km}$ & $6.75 \mathrm{dBm}$ & $2.93 \mathrm{e}^{-010}$ \\
\hline Moderate Fog & $2.8 \mathrm{~km}$ & $6.75 \mathrm{dBm}$ & $2.737 \mathrm{e}^{-010}$ \\
\hline
\end{tabular}

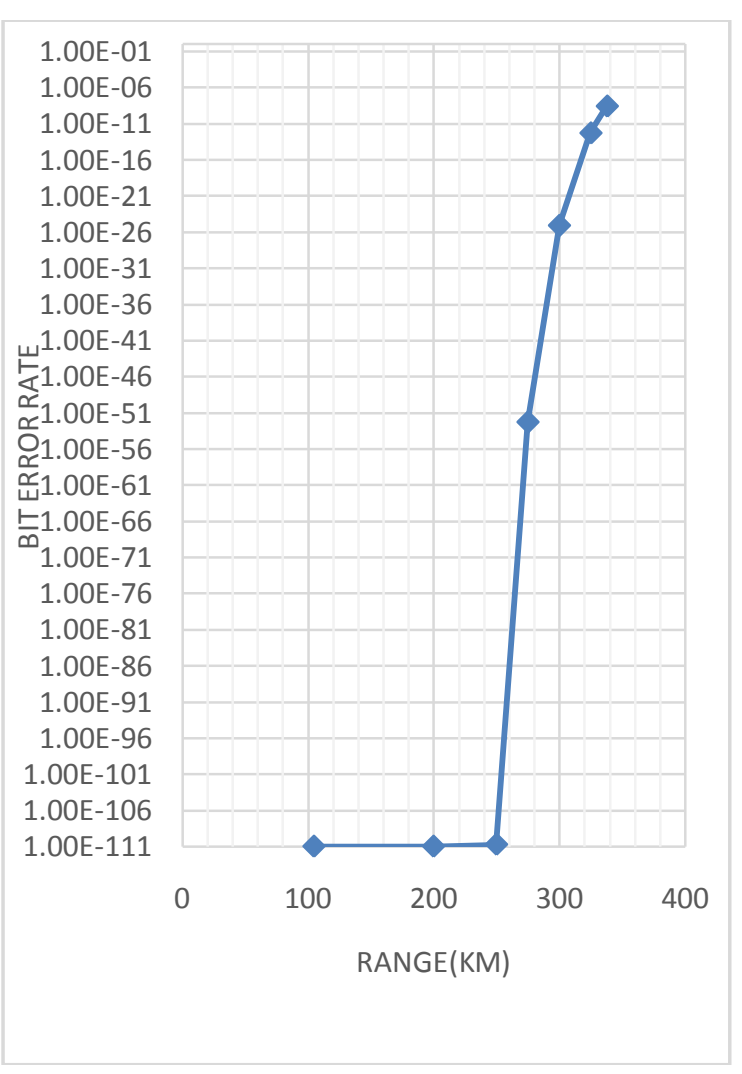

Fig. 4: bit error rate versus distance for system 1

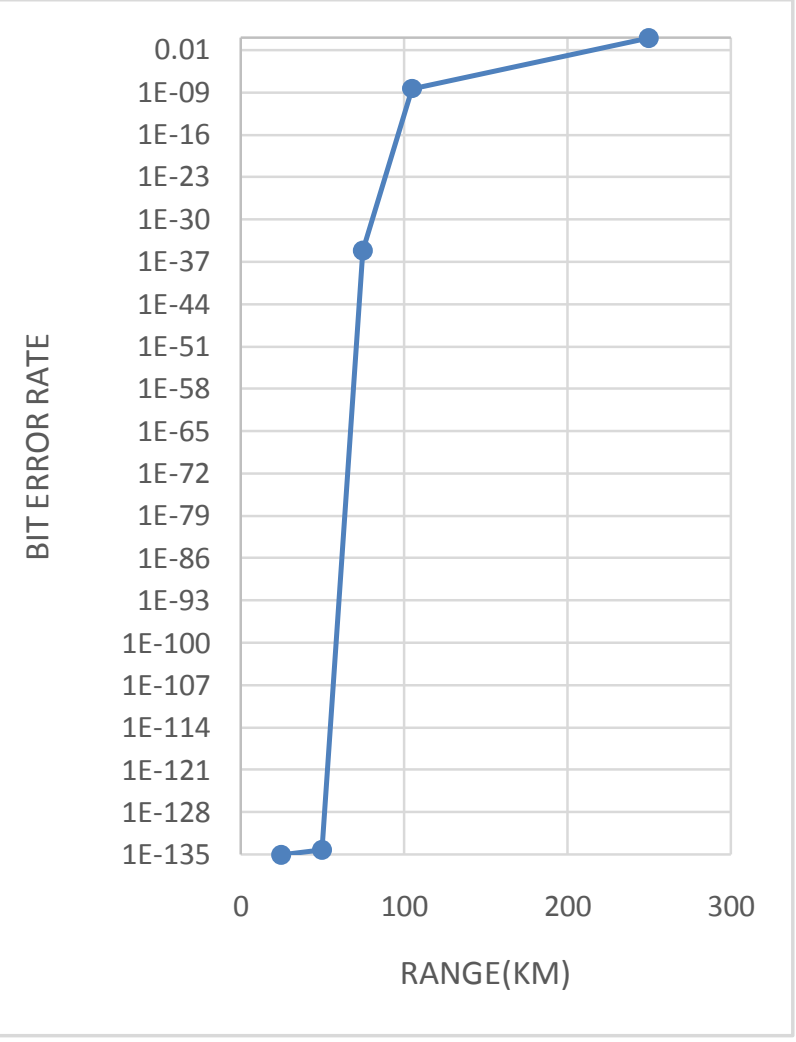

Fig. 5: bit error rate versus distance for system 2

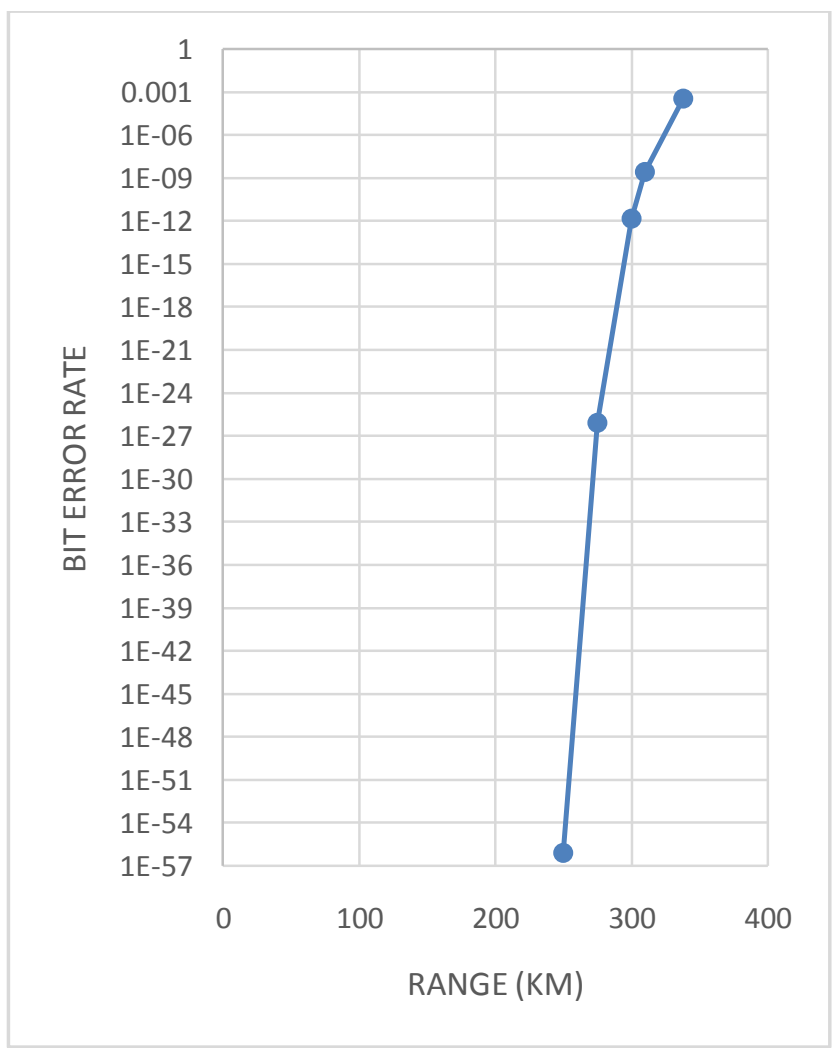

Fig. 6: bit error rate versus distance for system 3 


\section{IV.CONCLUSION}

The aim of this work is to investigate a multiple transmitter/receiver FSO link which is integrated with different types of amplifications. Three types of systems are studied in this work. System 1 shows the best BER performance and gives maximum range of $338 \mathrm{~km}$ within acceptable received power .System 2 using post amplification is not a good option as its BER is quite high and maximum range is just up to $100 \mathrm{~km}$. System 3 uses both pre and post amplification shows superior performance than system 2 but its BER is higher than system 1 though its received power is good. So it can be concluded that preamplification is a better option as it has good BER performance within acceptable received power and is lesser costly and complex than system 3 .

\section{ACKNOWLEDGMENT}

The authors would like to thank Guru Nanak Dev University (GNDU) for providing us with optisystem software.

\section{REFERENCES}

[1]. Scott Bloom, Eric Korevaar, John Schuster and Heinz Willebrand "Understanding the performance of free-space optics", Journal of optical networking, vol.2, No 6, June 2003

[2].Valerio Annovazzi-Lodi, Giuseppe Aromataris, Mauro Benedetti and Sabina Merlo, "Secure chaotic transmission on a free-space optics data link", IEEE Journal of quantum electronics, Vol. 44, No. 11, November 2008

[3]. Sushank Chaudhary, Angela Amphawan, Kashif Nisar, "Realization of free space optics with OFDM under atmospheric turbulence", journal of optic (2014) in science direct

[4].A.Z. Suriza , Islam Md Rafiqul,A.K.Wajdi,A.W.Naji, "Proposed parameters of specific rain attenuation prediction for free space optics link operating in tropical region", Science Direct journal of atmospheric and solar terrestrial physics $94(2013)$

[5]Hilal A. Fadhil, Angela Amphawan, Nasim Ahmed, "Optimization of free space optics parameters: An optimum solution for bad weather conditions "Science Direct Journal of Optik 124(2013)

[6].Xian Liu, "Free-space optics optimization models for building sway and atmospheric interference using variable wavelength", IEEE transactions of communication, Vol.57, No.2, February 2009

[7]. Gilberto Kirk Rodrigues, Vitor Gouvea,Andrezo Carneiro,Alberto Rubin da Cruz, Maria Thereza M. Rocco, "Evaluation of the strong turbulence impact over free space optical links", Science Direct journal on Optics communications305(2013)

[8]. Nazmi A. Mohammed, Amr S. El-Wakeel* and Mostafa H. Aly, "Performance evaluation of FSO link under NRZ-RZ line codes, different weather conditions and receiver types in the presence of pointing errors", The Open Electrical \& Electronic Engineering Journal, 2012 ,Bentham [9]. Nazmi A. Mohammad, Amur S. El Wakeel and Modtafa H. Aly, "Pointing error in FSO link under different weather conditions", International journal of Video \& Image processing and network security IJVIPNS-IJENS Vol:12 No:01

[10]. Xiaoming Zhiu and Joseph M. Fellow, "Free space optical communication through atmospheric turbulence channels"IEEE transactions on communications, Vol. 50, No. 8, august 2002

[11] S.A. Al-Gailani, A.B. Mohammad, R.Q. Shaddad, "Enhancement of free space optical link in heavy rain attenuation using multiple beam concept "Science Direct journal on optic, 124 (2013)

[12]. Nur Haedzerin M D Noor, Ahmed Wathik Nazi and Wazdi ALKhateeb "Performance Analysis of a free space optics link with Multiple transmitters/receivers", IIUM Engineering Journal, Vol.13 No.1, 2012 